\title{
PENERAPAN E-COMMERCE PADA KELOMPOK PKK DI KELURAHAN PABUARAN - CIBINONG
}

\author{
Rahmatika $^{1)}$, Harry Dhika ${ }^{2)}$, Nasrulloh Isnain ${ }^{3)}$ \\ Program Studi Informatika, Fakultas Teknik dan Ilmu Komputer, Universitas Indraprasta PGRI
}

\begin{abstract}
Abstrak
Penggunaan E-commerce dalam teknologi informasi semakin meningkat. Salah satu $e$ commerce yang sering digunakan akhir-akhir ini adalah marketplace. Dari sekian banyak yang marketplace yang tersedia, shopee adalah marketplace yang sering digunakan pelanggan, termasuk ibu-ibu PKK (Pemberdayaan dan Kesejahteraan Keluarga). Selama ini ibu-ibu PKK hanya berperan sebagai pelanggan tanpa menyadari potensi keuntungan finansial yang dapat diraih. Maka dari itu kami menyelenggarakan kegiatan abdimas dengan bentuk pembelajaran dan pemberian pelatihan berniaga menggunakan marketplace shopee. Kegiatan ini secara khusus bertujuan untuk membekali ibu-ibu PKK di kelurahan PabuaranCibinong dalam memaksimalkan marketplace shopee agar dapat berperan aktif dalam kegiatan perniagaan yang menghasilkan keuntungan finansial. Memaksimalkan market place shopee dapat meningkatkan penjualan dan meminimalisir pengeluaran karena tidak memerlukan toko fisik, biaya promosi atau biaya untuk membayar karyawan. Apalagi jika penjualannya masih dalam skala kecil, khususnya ibu-ibu PKK yang dapat melakukan penjualan tanpa harus meninggalkan kegiatan mereka sehari- hari sebagai ibu rumah tangga.
\end{abstract}

Keywords: Market Place, Penjualan, Shopee, PKK

\begin{abstract}
Using E-commerce in information technology is getting more and more common. One of them that is commonly used is marketplace. From several marketplace available Shopee is familiar among customers including the housewives as the member of Family Welfare Program (PKK). Traditionally, the housewives as the member of Family Welfare Program only play a role a passive customer without realizing the financial potential they can achieve. That is the reason why we hold a voluntary program by providing education and training to trade using Shopee as the marketplace. This voluntary program itself is specifically intended to educate the housewives as the members of Family Welfare Program in PabuaranCibinong in order to be able to use Shopee marketplace so that they can get the best financial profit. Using Shopee marketplace can increase the sale and reduce the expense since it doesn't need real shop, advertising cost or employee salary. Moreover, it will be more beneficial when it is small-scale business run by the housewives without the need to abandon their duty as a housewife.
\end{abstract}

Keywords: Market Place, Selling, Shopee, PKK

Correspondence author: Rahmatika, rahmanasrul@gmail.com, Jakarta, Indonesia

This work is licensed under a $C C-B Y-N C$ 


\section{PENDAHULUAN}

Pertumbuhan dunia e-commerce dalam teknologi informasi semakin meningkat, dengan menjamurnya penggunaan marketplace para pelaku usaha berlomba-lomba untuk membuat marketplace dengan model tampilan yang sangat menarik, enak dilihat, mudah digunakan oleh pelaku usaha maupun calon konsumen serta disuguhkan dengan promosipromosi yang sangat menarik, setiap marketplace mencoba memberikan kesan tersendiri bagi penggunanya contohnya shopee, bukalapak, tokopedia dan lain sebagainya, mereka mencoba memberikan image marketplacenya sedemikian rupa untuk menarik perhatian calon konsumen dan penjual supaya mudah dikenal oleh masyarakat luas.

Dunia perniagaan pun sekarang meminimalisir pengeluaran yang dibutuhkan dalam mempromosikan barang dagangan mereka. Mereka yang berkecimpung didalam dunia perniagaan biasanya lebih memilih aplikasi yang gampang digunakan dan paling banyak digunakan sehingga dalam perjualannya pun semakin meningkat karena banyak peluang bagi para pelaku usaha tersebut barang dagangannya dapat dilihat oleh pengguna marketplace tersebut.

Shopee mencoba memberikan image dengan dominan warna orange serta dengan slogan yang khasnya yang terkenal dengan gratis ongkir bagi penggunanya. Dengan banyaknya marketplace yang sudah tersedia akan tetapi banyak pelaku usaha yang belum memanfaatkannya dalam berniaga, kebanyakan masyarakat menggunakannya hanya dalam belanja online. Pemanfaatan marketplace shoope dirasa cukup meningkatkan penjualan dan sangat minim dalam pengeluaran karena tidak memerlukan toko fisik, biaya promosi atau biaya untuk membayar karyawan jika penjualannya masih dalam skala kecil yang dilakukan oleh usahawan khususnya ibu-ibu PKK tanpa harus meninggalkan kegiatan mereka sehari- hari sebagai ibu rumah tangga.

Oleh karena itu tim abdimas dirasa perlu untuk mengadakan pembelajaran Kegiatan ini secara khusus bertujuan untuk membekali ibu-ibu PKK di kelurahan PabuaranCibinong dalam memaksimalkan marketplace shopee agar dapat berperan aktif dalam kegiatan perniagaan yang menghasilkan keuntungan. Kami mengharapkan pembelajaran maupun pelatihan yang sudah disampaikan dapat dikuti oleh ibu-ibu PKK agar menambah penghasilan mereka dalam penjualan melalui marketplace yang sudah tersedia, serta dapat memanfaatkan marketplace yang bijak. Oleh karenanya tim abdimas merasa perlu untuk mengadakan pembelajaran dan pelatihan bagi ibu-ibu PKK yang beralamatkan di Perumahan Pabuaran Asri 2 Kelurahan Pabuaran, Kecamatan Cibinong, Kabupaten Bogor.

\section{Maksud dan Tujuan}

Adapun tujuan dari pelaksanaan abdimas ini adalah sebagai salah satu tridarma perguruan tinggi melalui program iptek untuk masyarakat yaitu untuk meningkatkan pemahaman dan pengetahuan masyarakat terutama bagi ibu-ibu PKK mengenai penggunaan dan pembuatan sebuah toko di marketplace khususnya marketplace shopee untuk meningkatkan penjualan mereka. Target yang diharapkan dari kegiatan pengabdian masyarakat ini yang kami lakukan di ibu-ibu PKK adalah :

1. Meningkatkan pengetahuan kelompok PKK di kelurahan pabuaran melalui manfaat marketplace.

2. Meningkatkan pemahaman dan kompetensi dalam bidang teknologi khususnya manfaat dari marketplace untuk peningkatan penjualan dan mempromosikan barang yang akan dijual. 


\section{METODE PELAKSANAAN}

Kegiatan pengabdian masyarakat ini dilaksanakan di tempat terbuka di aula Perumahan Pabuaran Asri 2 yang beralamatkan di Perumahan Pabuaran Asri 2, Kelurahan Pabuaran, Kecamatan Cibinong, Kabupaten Bogor. Kegiatan pelaksanaannya dilakukan pada hari rabu tanggal 31 Juli 2019. Peserta terdiri dari ibu-ibu PKK yang berkecimpung didalam dunia perdagangan.

Metode pelaksanaan adalah metode pelatihan yaitu pemberian materi sekilas tentang shopee berikut materi cara penggunaan dan pembuatan toko online di shopee. Dalam kegiatan pengabdian ini selain menjelaskan dan pembuatan toko online di marketplace shopee juga diberikan cara pengoptimalkan shopee tersebut untuk menigkatkan penjualan mereka, yang dapat di akses bukan hanya di komputer tetapi di handphone.

Pelaksanaan kegiatan ini dilakukan dalam tiga tahap, yakni tahap persiapan, pelaksanaan dan evaluasi.

1. Tahap Persiapan, pada tahap ini tim melakukan survei pendahuluan untuk mengetahui kondisi target kegiatan dengan menganalisis kondisi tempat yang akan digunakan, kondisi peserta yang akan diberikan perlakuan dan menyusun rancangan kegiatan yang akan dilakukan. Tahap persiapan selanjutnya tim menyiapkan bahan-bahan yang akan dijadikan materi persentasi.

2. Tahap Pelaksanaan yaitu, tim pelaksana melakukan Pelatihan kepada para ibu-ibu PKK dikelurahan Cibinong dengan menyampaikan materi mengenai bagaimana penggunaan teknologi khususnya marketplace untuk keperluan dalam mempromosikan barang yang dibuat atau ibu-ibu yang memiliki usaha.

3. Evaluasi dilakukan untuk mengukur tingkat keberhasilan suatu kegiatan pelatihan pemanfaatan teknologi marketplace untuk meningkatkan penjualan. Evaluasi dilakukan berupa pemberian angket untuk mengetahui tanggapan peserta (ibu-ibu PKK dikelurahan pabuaran) terhadap kegiatan pengabdian masyarakat.

\section{HASIL DAN PEMBAHASAN}

Pada bagian ini penulis membahas dan memaparkan tentang hasil pengabdian masyarakat yang dilaksanakan di Pabuaran Cibinong Jawa Barat, tepatnya diwilayah kelurahan Pabuaran komplek Pabuaran, mitra yang hadir merupakan ibu-ibu pkk yang memiliki kegiatan yang bermanfaat. Dimana ibu-ibu pkk adalah ibu rumah tangga yang ingin berniaga dalam marketplace shoope (Shopee, 2018). Dari pengamatan kami ibu-ibu pkk belum mengetahui cara penggunaan shoope didunia perniagaan. Bagaimana cara membuat tools di shopee(Sari et al., 2017), membuat atau mengupload produk dan lain sebagainya. Adapun hasil yang didapat dalam pengabdian masyarakat ini adalah membuat ibu-ibu pkk mampu menggunakan marketplace bukan hanya dalam hal belanja atau membeli tetapi berguna dalam hal berniagaan. Adapun hasil lain yang didapat adalah

1. Meningkatkan pengetahuan kelompok PKK di kelurahan pabuaran melalui manfaat marketplace.

2. Meningkatkan pemahaman dan kompetensi dalam bidang teknologi khususnya manfaat dari marketplace untuk peningkatan penjualan dan mempromosikan barang yang akan dijual. 
Materi seminar dilakukan dan dibawakan khsusnya oleh ibu Rahmatika, M.Kom

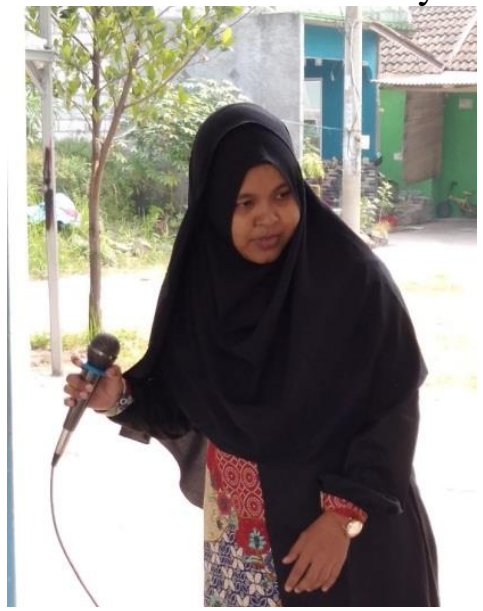

Gambar 1. Ibu Rahmatika Menerangkan Materi Market Place

Materi secara khusus dibuat dan dibawakan oleh ibu Rahmatika, materi dan implementasi terlampir dan kegiatan uji coba langsung dilakukan sehingga bersifat workshop.

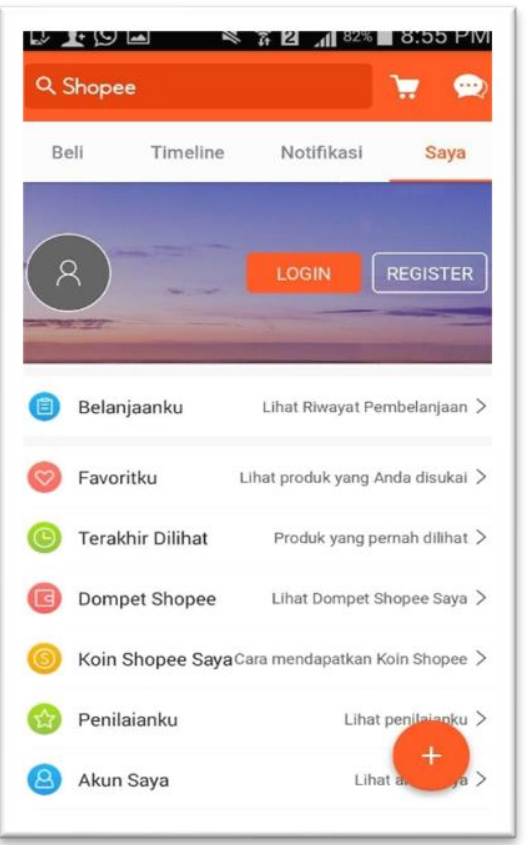

Gambar 2. Mobile Apps Shope, Halaman Utama

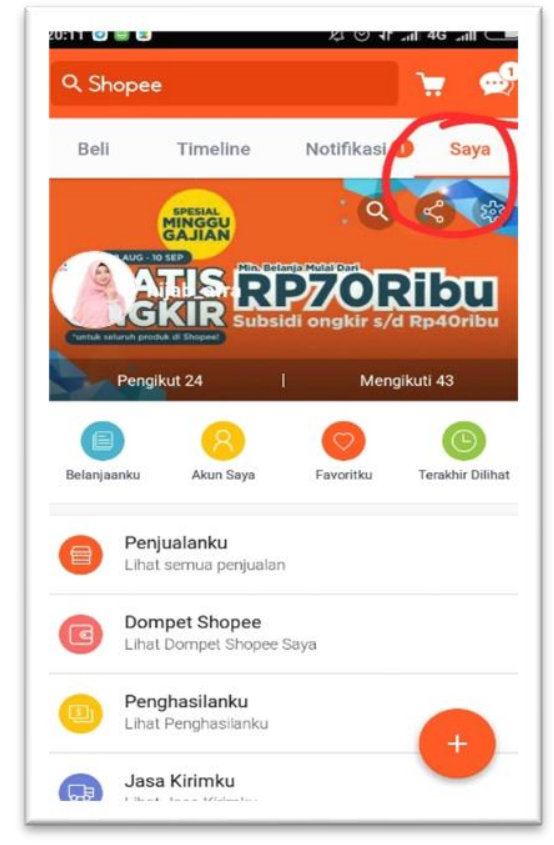

Gambar 3. Halaman setelah melakukan Login 


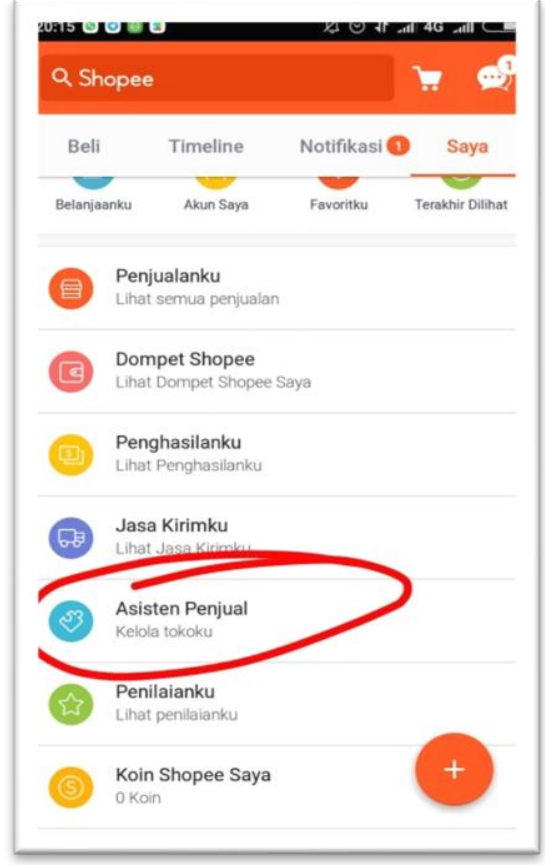

Gambar 4. Menu Kelola Toko dengan asisten Penjual Login

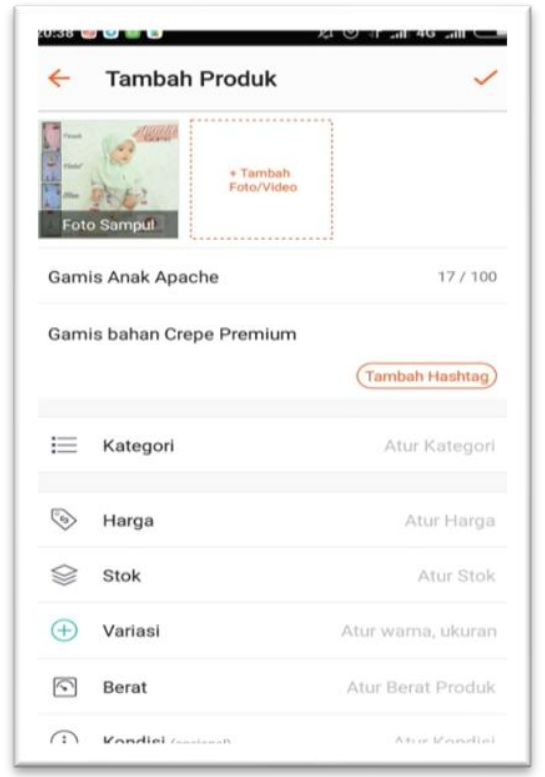

Gambar 6. Menu Tambah Produk yang akan dijual

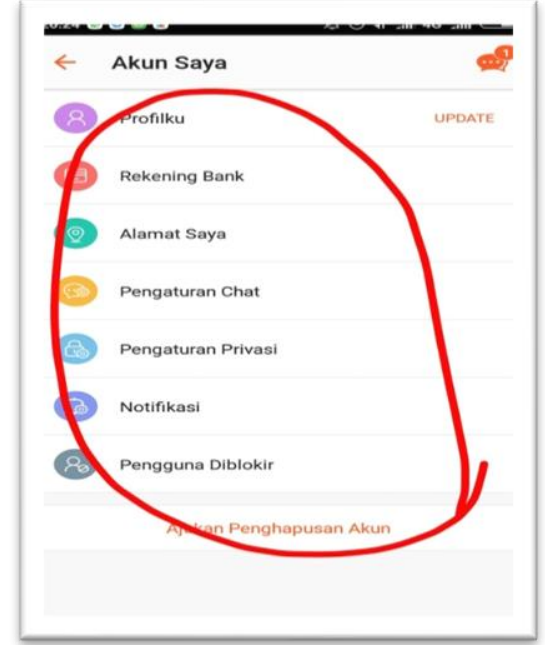

Gambar 5. Mengisi data Pribadi

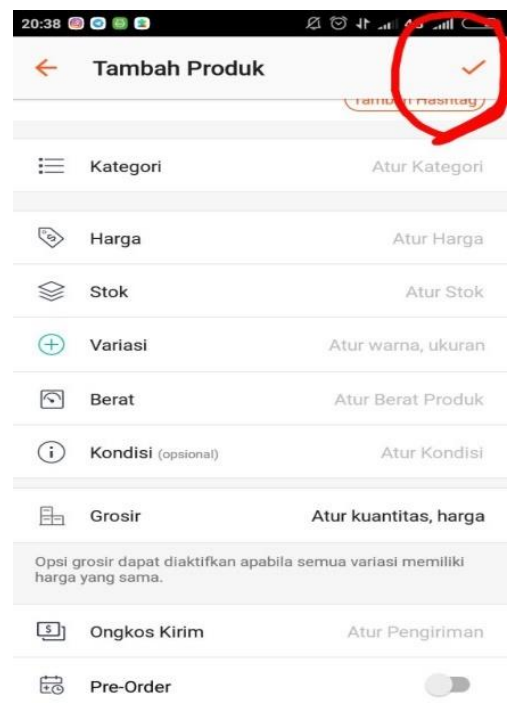

Gambar 7. Kelengkapan Tambah Produk

Dari pelaksanaan kegiatan terlihat peserta sangat antusias karena pentingnya kegiatan untuk membantu sedikit perekonomian warga, diharapkan dengan pelatihan ini memberikan banyak manfaat dan terutama mengisi waktu luang yang diakukan oleh ibu rumah tangga, namun jika serius mengembangkan maka bisnis seperti shoping atau menjual barang dari rumah dengan marketplace ini merupakan sebuah kegiatan yang menjanjikan kedepannya untuk dijadikan bisnis utama keluarga. 


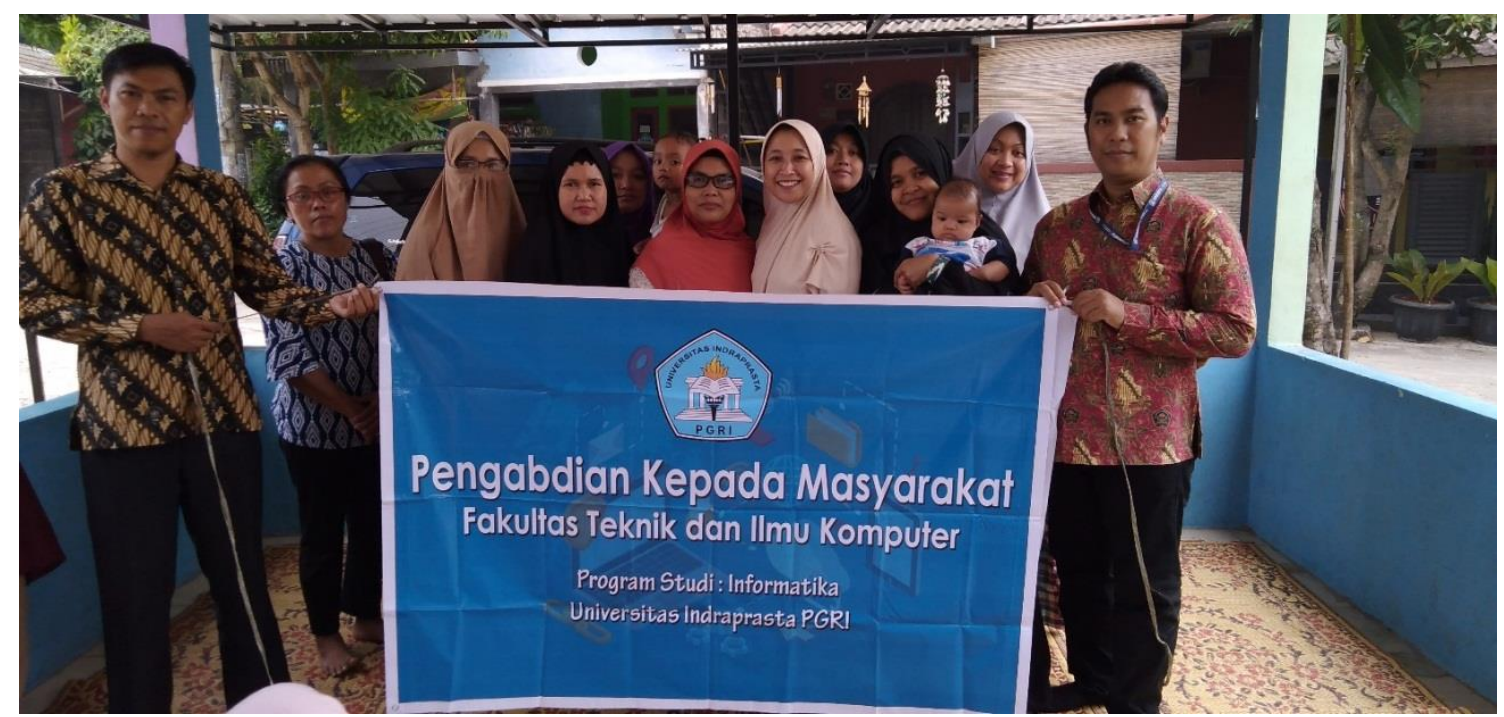

Gambar 8. Antusias warga sangat baik menyambut teknologi Marketplace dalam Wirausaha dilingkungan Keluarga

\section{SIMPULAN}

Kegiatan yang dilakukan sangat bermanfaat sekali, hal tersebut terlihat dalam pelaksanaan kegiatan menerima marketplace sebagai salah satu usaha untuk mengembangkan usaha atau mengisi waktu luang keluarga.

Implementasi mobile aplikasi untuk marketplace Shopee (Hakim, 2019; Pengabdian et al., 2018; Sari et al., 2017) dinilai layak diterapkan karena banyak keluarga dilingkungan kelompok PKK Sangat antusias dengan pelaksanaan kegiatan ini. Penggunaan marketplace itu diperlukan dalan hal perniagaan sehingga dapat meningkatkan penjualan dan membantu keluarga dalam mengisi waktu luang.

Hal lain yakni meningkatkan pengetahuan dalam bidang marketplace sehingga banyak manfaat yang diperoleh, walau awalnya hanya menjual beberapa produk namun lama kelamaan akan lebih berpengalaman dan terus berkembangan melalui jaringan marketplace.

\section{DAFTAR PUSTAKA}

Hakim, L. (2019). Pelatihan Pemasaran Online Berbasis Marketplace Bagi UMKM Dalam Merespon Perubahan Perilaku Konsumen, II, 74-91.

Pedro, J., \& Ortiz, M. (2018). Pengaruh Tagline Shopee Terhadap Keputusan Pembelian Pada Mahasiswa Ilmu Komunikasi Uin Sunan Ampel Surabaya. Universitas Islam Negeri Sunan Ampel Surabaya Fakultas. Retrieved from https://www.google.com/url?sa=t\&rct=j\&q=\&esrc=s\&source=web\&cd=7\&cad $=$ rja\&uact=8\&ved=2ahUKEwj39enk6N7jAhWBiXAKHUkcDn4QFjAGegQI CBAC\&url=http\%3A\%2F\%2Fdigilib.uinsby.ac.id\%2F26328\%2F1\%2FSiti\%2 520Roykhanah_B06214019.pdf\&usg=AOvVaw2LW2TGfeLyWLYOGnyCwS $\underline{\mathrm{Z}}$ 
Pengabdian, J., Masyarakat, K., \& Harsa, P. (2018). Pelatihan Aplikasi Teknis Online Marketplace Pada Sentra UMKM Banyumas "Pratistha Harsa ” Untuk Pemasaran Produk Secara Online. Jurnal Abdimas BSI, 1(3), 593-599.

Sari, A. K., Ramansyah, W., Ningsih, P. R., Risnasari, M., Arif, M., Saputro, S. D., \& Effindi, M. A. (2017). Pelatihan Pemanfaatan E-Commerce Bagi Peningkatan Mutu Sosial Tenaga Kerja dan Wanita di Kelurahan Rongtengah Sampang Madura. Aksiologiya: Jurnal Pengabdian Kepada Masyarakat, 1(2), 151. https://doi.org/10.30651/aks.v1i2.931

Shopee. (2018). 10 Usability Heuristics by Nielsen; Lazada and Shopee Review. Retrieved from https://zikrohnafiah.files.wordpress.com/2018/05/gui-usabilityheuristics-report.pdf\%0A\%0A 